\title{
Análise da variação espacial físico-química de materiais superficiais da bacia hidrográfica do córrego do Glória-Uberlândia-MG
}

\author{
Analysis of the physical-chemical spatial variation of surfacial \\ materials of the Gloria Watershed - Uberlândia-MG
}

\author{
Fabiana Cristina dos Santos ${ }^{1}$ \\ Silvio Carlos Rodrigues ${ }^{2}$
}

\begin{abstract}
Resumo
A distribuição dos materiais superficiais nas vertentes em ambiente de Cerrado dispõe de particularidades intrínsecas, que estão relacionadas com o posicionamento topográfico, formato das vertentes e com escoamento superficial da água. Todos estes aspectos estão associados com a sazonalidade climática, típica deste ambiente. Dessa forma, este trabalho objetiva investigar, os atributos físico-químicos e sua relação com os materiais superficiais-paisagens, concernentes com as características geomorfológicas, influenciadas por sua variabilidade espacial, a qual exerce papel preponderante na qualidade destes ecossistemas. A área de estudo trata-se de uma bacia hidrográfica localizada no município de Uberlândia, na região sudeste do Triângulo Mineiro. A metodologia baseou-se na análise das propriedades físicas, químicas e mapeamento da distribuição espacial dos mesmos através de técnicas de Krigagem. Foram analisados: textura; densidade aparente; porosidade total; matéria orgânica; $\mathrm{CTC}, \mathrm{V}, \mathrm{H}+\mathrm{Al}, \mathrm{pH}$, $\mathrm{K}^{+}$, hipsometria e uso e cobertura da terra, além de três mapas contendo as porcentagens de argila, silte e areia para a elaboração do mapa exploratório do terreno para toda bacia hidrográfica. Cerca de $80 \%$ da bacia está ocupada por agropecuária e ação antrópica. A análise prognóstica correlacionou os atributos físico-químico de forma subjetiva, por se tratar de um estudo embasado em probabilidades, considerando o conhecimento disponível sobre cada atributo na literatura especializada. A análise dos materiais superficiais, somada aos atributos mapeados oferece informações importantes, dotada de grande valor geográfico, seja no âmbito da geomorfologia, seja no que se refere aos estudos do meio físico integrados aos setores de planejamento e gestão ambiental.
\end{abstract}

Palavras-chave: Atributos físico-químicos, geoquímica superficial, geomorfologia de vertente materiais superficiais-paisagem

\footnotetext{
${ }^{1}$ Universidade Federal de Uberlândia, Programa de Pós-Graduação em Geografia. Uberlândia, MG, Brasil. fabianaqgufu@gmail.com

${ }^{2}$ Universidade Federal de Uberlandia, Uberlândia, MG, Brasil. silgel@ufu.br

Artigo recebido em: 22/10/2018. Aceito para publicação em: 04/02/2019.
} 


\begin{abstract}
The distribution of surface materials in the Cerrado environment has intrinsic characteristics which are related to topographic positioning, slope shape and water runoff. All these aspects are associated with climatic seasonality typical of this environment. In this way this work aims to investigate the physical and chemical attributes of the surface materials concerned with the geomorphological characteristics influenced by their spatial variability which plays a predominant role in the quality of these ecosystems. The study area is a hydrographic basin located in the county of Uberlândia in the southeast region of the Triângulo Mineiro. The methodology was based on the analysis of the physical, chemical and mapping of some parameters. We analyzed: texture, apparently density, total porosity, organic matter, $\mathrm{CTC}, \mathrm{V}, \mathrm{H}+\mathrm{Al}, \mathrm{pH}, \mathrm{K}+$, hypsometry and use and coverage. In addition to three maps containing the percentages of clay, silt and sand for the elaboration of the exploratory map and its peripherals of the hydrographic basin. About $80 \%$ of the basin is occupied by agriculture and anthropogenic action. The prognostic analysis correlated the physicalchemical attributes subjectively because it is a study based on probabilities considering the available knowledge about each attribute in the national literature. The analysis of the superficial materials added to the mapped attributes offers to the researchers important information endowed with great geographic value, be it in the scope of the geomorphology, or in what refers to the studies of the physical environment integrated to the sectors of planning and environmental management..
\end{abstract}

Keywords: Physical and chemical attributes, Surface Geochemistry, Hillslope Geomorphology.

\title{
Introdução
}

O ambiente de Cerrado possui particularidades que resultam em distribuição dos fluxos de matéria e energia dentro dos sistemas de bacias hidrográficas. A conformação das vertentes nestas bacias acaba por afetar também o arranjo dos materiais superficiais, bem como o uso da terra existente. A área de estudo escolhida para esta pesquisa está localizada em um ambiente predominantemente erosivo, onde a distribuição dos materiais superficiais, incluindo solos e depósitos, obedece a combinação destas condições e elementos.

Considerando a natureza textural dos materiais superficiais, nota-se a importância de sua participação, para análises quantitativas, uma vez que contribui para classificar os seus elementos constituintes, tratando-se de uma característica estável, pois os tamanhos das partículas de material mineral não estão sujeitos à mudanças rápidas, além do fato que a proporção de cada grupo de fração, não poderá ser alterado. 
De acordo com Santos, Barcelos e Rodrigues (2015), os materiais superficiais estão constantemente em atividade química, onde inúmeras reações se processam ao mesmo tempo, dentro de cada uma de suas fases (sólida, líquida e gasosa), entre elas e delas com o ambiente. Devido a sua alta reatividade, a maioria dos fenômenos químicos ocorre nas partículas menores, chamada fração coloidal.

Nesse contexto, o objetivo geral da pesquisa foi caracterizar os atributos físicos e químicos dos materiais superficiais da bacia hidrográfica do Córrego do Glória, a fim de avaliar propriedades que possam ser utilizadas para a reflexão sobre a relação materiais superficiais-paisagem, por tratar-se de uma área totalmente modificada pelas ações humanas e por processos de pedogênese e morfogênese.

\section{Área de Estudo}

A pesquisa em questão foi desenvolvida na Bacia Hidrográfica do Glória, nas coordenadas geográficas de $18^{\circ} 56^{\prime} 56^{\prime \prime}$ de latitude Sul e $48^{\circ} 12^{\prime} 21^{\prime \prime}$ de longitude Oeste de Greenwich, com altitude entre 920 e 865 metros acima do nível do mar, situada no município de Uberlândia - MG, conforme observase na Figura 1.

De acordo com Alves (2007), nesta área as estações, chuvosa e seca, duram cerca de seis meses cada, devido ao deslocamento da área de influência das massas de ar que atuam sobre a região, que são elas: Massa Equatorial Continental, a Tropical Atlântica e a Massa de Ar Polar. 
Figura 1:-Mapa de localização da área de estudo e pontos de coleta amostral.

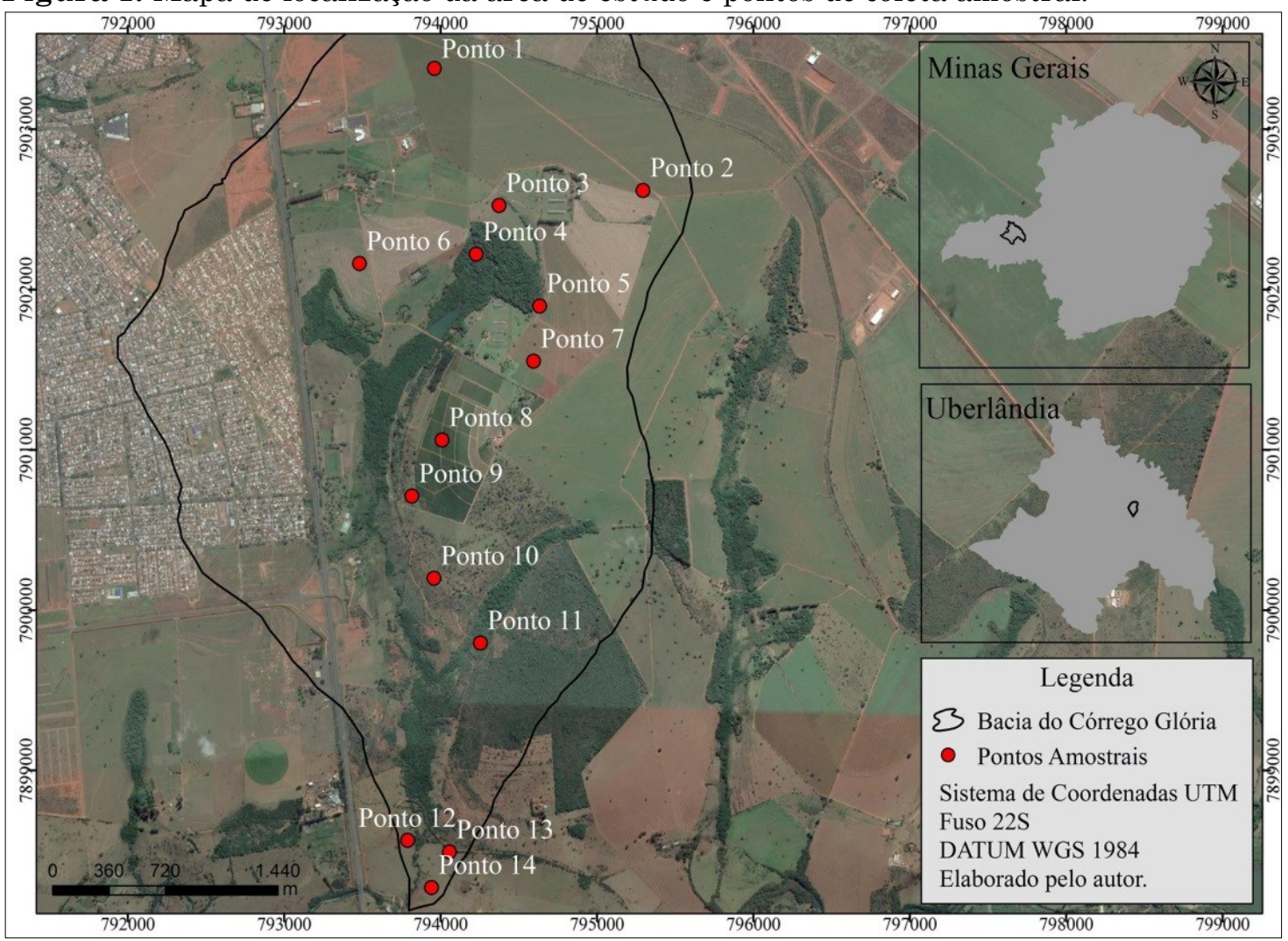

Org.: autores, 2018.

Segundo Ab'Saber (1977) o Domínio Morfoclimático do Cerrado é caracterizado por chapadões cobertos por vegetação de cerrado e penetrado por floresta-galeria ao longo dos cursos d'água. A vegetação natural da área de estudo é dividida em três tipos, ocorrendo cerrado senso restrito, mata mesofitica e campo úmido.

A litologia da bacia hidrográfica do Córrego do Glória, caracteriza-se pelos sedimentos cenozoicos (Depositos Detritico-Lateriticos) na área de topos planos e mesozoicos (Formação Marilia) nas vertentes que recobrem quase que a totalidade da bacia, sendo constituídos de leitos de cascalheiras, arenitos heterogêneos e mal selecionados, sendo que nos fundos de vales afloram basaltos (Formação Serra Geral). Alves (2007), destaca que devido ao intemperismo, atualmente se verificam poucas características estruturais originais das rochas. O padrão de forma de relevo da área de estudo, de acordo com Costa, Barcelos e Rodrigues (2018), apresentam colinas e superfícies aplainadas nos topos. 


\section{Procedimentos Operacionais}

Os procedimentos operacionais foram realizados em tres etapas. Primeiramente foram feitos levantamentos bibliográficos e cartográficos para identificação da área de estudo. Em um segundo momento foram escolhidas a tipologia de abordagem em relação a materiais a serem coletados e quais mapas seriam produzidos, bem como foram realizados trabalhos de campo para coleta dos materiais. Em um terceiro momento foram feitas as análises e construídos os elementos de interpretação (mapase tabelas).

Os trabalhos de campo foram realizados com visitas à bacia hidrográfica do Córrego do Glória com objetivo de coletar amostras de materiais superficiais, para avaliação das análises físicas: densidade aparente (Da), porosidade total $(\mathrm{Pt})$ e textura (T). E análises químicas: $\mathrm{pH}$, $\mathrm{K}$ (potássio), Ca(cálcio), H+Al(alumínio trocável), CTC, V\% (saturação por base) e MO. A amostragem contou com coletas de amostras simples em 14 pontos na escala da bacia hidrográfica (Figura 1), levando-se em consideração a topografia, forma da vertente e distribuição casualizada dentro das variações encontradas destes elementos.

A etapa envolvendo a fase laboratorial de análises físicas foram realizadas no LAGES- Laboratório de Geomorfologia e Erosão dos Solos e as análises químicas foram terceirizadas no laboratório da GEAP - Agrociências. As principais informações sobre as análises físico-químicas estão apresentadas na Tabela 1.

Tabela 1: Parâmetros físico-químicos avaliados para a área de estudo.

\begin{tabular}{|c|c|c|c|c|}
\hline \multicolumn{2}{|c|}{ Parâmetros } & Unidade & Método & $\begin{array}{c}\text { Profundidade de } \\
\text { coleta }\end{array}$ \\
\hline \multirow{6}{*}{ Químico } & $\mathrm{pH}$ & & pH em $\mathrm{H}_{2} \mathrm{O}$-Embrapa(1997) & Trado holandês $0-10 \mathrm{~cm}$ \\
\hline & $\mathrm{K}$ & $\mathrm{cmol} \cdot \mathrm{dm}^{-3}$ & Colometria -Vettori(1969) & Trado holandês $0-10 \mathrm{~cm}$ \\
\hline & $\mathrm{Ca}$ & $\mathrm{cmol} . \mathrm{dm}^{-3}$ & Titulometria-Embrapa(1997) & Trado holandês $0-10 \mathrm{~cm}$ \\
\hline & CTC & $\mathrm{cmol} . \mathrm{dm}^{-3}$ & Embrapa (1997) & Trado holandês $0-10 \mathrm{~cm}$ \\
\hline & $\mathrm{H}+\mathrm{Al}$ & $\mathrm{cmol} \cdot \mathrm{dm}^{-3}$ & Embrapa (1997) & Trado holandês $0-10 \mathrm{~cm}$ \\
\hline & $\mathrm{V}$ & $\%$ & Embrapa (1997) & Trado holandês $0-10 \mathrm{~cm}$ \\
\hline \multirow{4}{*}{ Físicos } & $\mathrm{MO}$ & dag.k ${ }^{-1}$ & Método adaptado Daniels (1971) & Trado holandês $0-10 \mathrm{~cm}$ \\
\hline & $\mathrm{Da}$ & g.cm ${ }^{3}$ & Anel volumétrico-Embrapa (1997) & $\begin{array}{l}\text { Amostra indeformada } 0- \\
10 \mathrm{~cm}\end{array}$ \\
\hline & PT & $\%$ & Embrapa (1997) & Amostra indeformada 0- \\
\hline & Textura & $\%$ & Embrapa (1997) & $\begin{array}{l}10 \mathrm{~cm} \\
\text { Trado holandês } 0-10 \mathrm{~cm}\end{array}$ \\
\hline
\end{tabular}

Org.: autores, 2018. 
Foram utilizados pontos amostrais georreferenciados (Tabela 2) e baseado nos dados gerados pelos ensaios laboratoriais foi gerado uma interpolação do tipo Krigagem (método ordinário, com semivariograma esférico, estendendo a área de abrangência do processamento por um retângulo envolvente, criado manualmente).

Tabela 2: Caracterização dos pontos amostrais.

\begin{tabular}{|c|c|c|c|c|c|}
\hline \multirow{2}{*}{$\begin{array}{c}\text { Pontos } \\
1\end{array}$} & \multicolumn{2}{|c|}{$\begin{array}{c}\text { Coordenadas } \\
\text { Latitude/Longitude }\end{array}$} & \multirow{2}{*}{$\begin{array}{c}\text { Uso e } \\
\text { Ocupação } \\
\text { cultura }\end{array}$} & \multirow{2}{*}{$\begin{array}{r}\text { Altitude } \\
945\end{array}$} & \multirow{2}{*}{$\begin{array}{r}\begin{array}{c}\text { Forma da } \\
\text { vertente }\end{array} \\
\text { Plano }\end{array}$} \\
\hline & $18^{\circ} 58^{\prime} 17,2^{\prime \prime}$ & $48^{\circ} 12^{\prime} 21,5^{\prime \prime}$ & & & \\
\hline 2 & $18^{\circ} 58^{\prime} 16,7^{\prime \prime}$ & $48^{\circ} 12^{\prime} 21,3^{\prime \prime}$ & Cultura & 945 & Plano \\
\hline 3 & $18^{\circ} 58^{\prime} 16,4^{\prime \prime}$ & $48^{\circ} 12^{\prime} 21^{\prime \prime}$ & cultura & 925 & Côncava \\
\hline 4 & $18^{\circ} 58^{\prime} 15,9^{\prime \prime}$ & $48^{\circ} 12^{\prime} 21^{\prime \prime}$ & vegetação & 903 & Côncava \\
\hline 5 & $18^{\circ} 58^{\prime} 15,8^{\prime \prime}$ & $48^{\circ} 12^{\prime} 20,5^{\prime \prime}$ & vegetação & 912 & Retilínea \\
\hline 6 & $18^{\circ} 58^{\prime} 16,3^{\prime \prime}$ & $48^{\circ} 12^{\prime} 18,7^{\prime \prime}$ & cultura & 897 & Côncava \\
\hline 7 & $18^{\circ} 58^{\prime} 17,1^{\prime \prime}$ & $48^{\circ} 12^{\prime} 19,4^{\prime \prime}$ & cultura & 908 & Retilínea \\
\hline 8 & $18^{\circ} 58^{\prime} 17,6^{\prime \prime}$ & $48^{\circ} 12^{\prime} 19,8^{\prime \prime}$ & cultura & 882 & Convexa \\
\hline 9 & $18^{\circ} 58^{\prime} 17,5^{\prime \prime}$ & $48^{\circ} 12^{\prime} 20,5^{\prime \prime}$ & pastagem & 870 & Convexa \\
\hline 10 & $18^{\circ} 58^{\prime} 17,8^{\prime \prime}$ & $48^{\circ} 12^{\prime} 21,6^{\prime \prime}$ & pastagem & 865 & Convexa \\
\hline 11 & $18^{\circ} 58^{\prime} 18,3^{\prime \prime}$ & $48^{\circ} 12^{\prime} 18,9^{\prime \prime}$ & vegetação & 847 & Côncava \\
\hline 12 & $18^{\circ} 58^{\prime \prime} 17,1^{\prime \prime}$ & $48^{\circ} 12^{\prime} 18,5^{\prime \prime}$ & pastagem & 814 & Convexa \\
\hline 13 & $18^{\circ} 58^{\prime} 16,6^{\prime \prime}$ & $48^{\circ} 12^{\prime} 17,8^{\prime \prime}$ & pastagem & 820 & Retilínea \\
\hline 14 & $18^{\circ} 58^{\prime} 16,4^{\prime \prime}$ & $48^{\circ} 12^{\prime} 18,1^{\prime \prime}$ & pastagem & 810 & Retilinea \\
\hline
\end{tabular}

Org.: autores, 2018.

Com base na krigagem gerada e utilizando as curvas de nível da carta topográfica, elaborou-se os polígonos que delimitam as áreas com predominância texturas específicas (arenosas, siltosas ou argilosas). Como procedimento final, elaborou-se o layout, dispondo os dados resultantes da krigagem de cada elemento físico-químico analisado na pesquisa. Para o mapa de uso e ocupação foi usada a técnica de vetorização manual por fotointerpretação. A composição da imagem é tipo cor natural.

\section{Resultados e Discussões}

Os resultados são apresentados em função da sequência das etapas estruturadoras deste estudo. As classes hipsométricas (Figura 2), representadas nos mapas temáticos, são importantes por favorecerem a delimitação das unidades topográficas, sendo as mesmas responsáveis pela definição dos limites entre um compartimento e outro. Sendo assim, avaliouse os desníveis topográficos da região de estudo, os quais demonstram o caimento do relevo, os padrões topográficos predominantes e as dimensões interfluviais. 
Figura 2; Mapa de hipsometria da área de estudo.

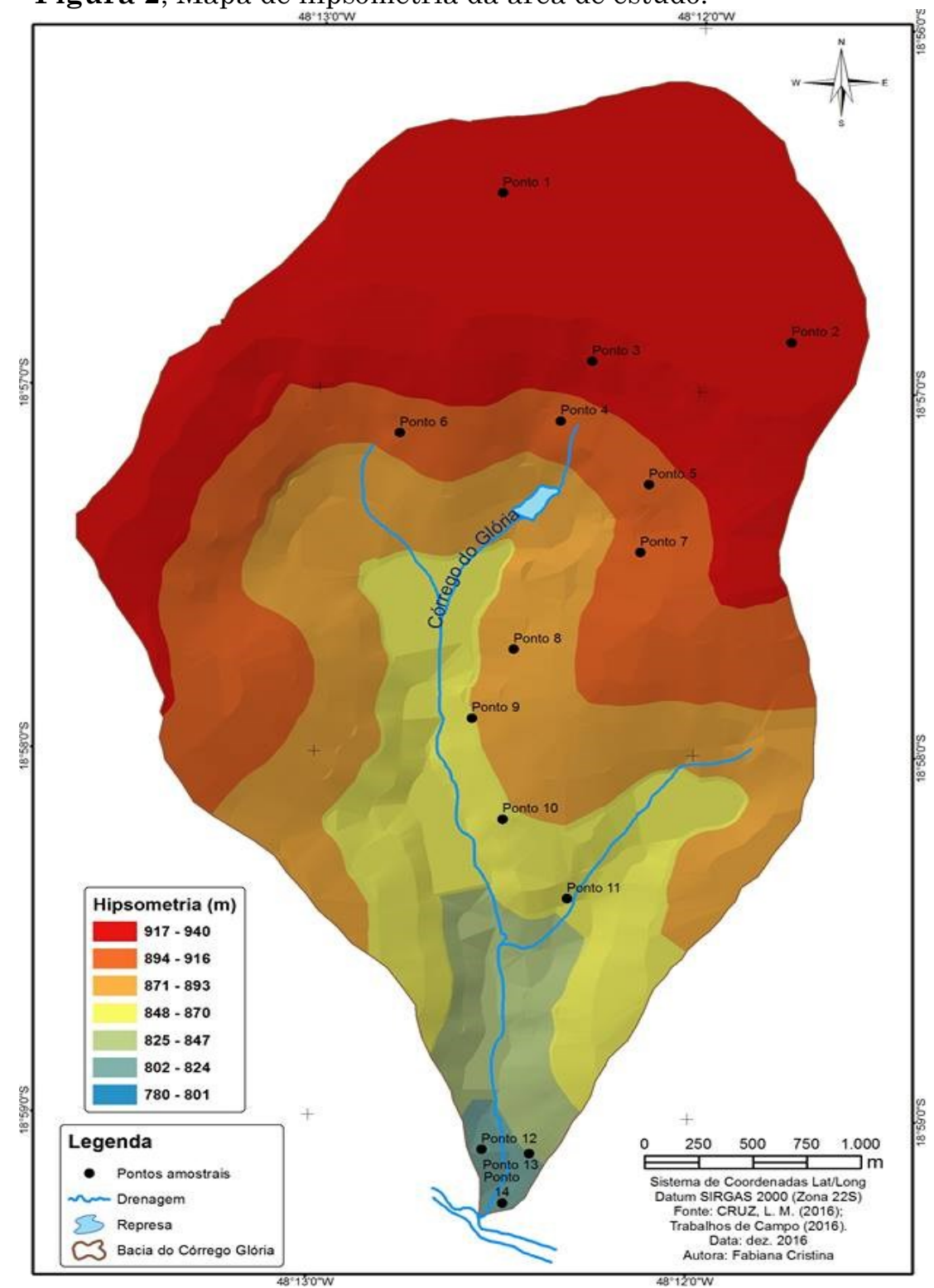

Org.: autores, 2018.

O uso e ocupação da terra da bacia hidrográfica encontra-se disposto no Figura 3. A área total equivale à $12.8 \mathrm{~km}^{2}$, onde se verifica uso e ocupações diversificadas. A quantificação dos diferentes tipos de uso e ocupação listados na Tabela 3 demonstra o predomínio de área de cultura (33,08\%). 
Figura 3: Mapa de uso e ocupação da área de estudo.

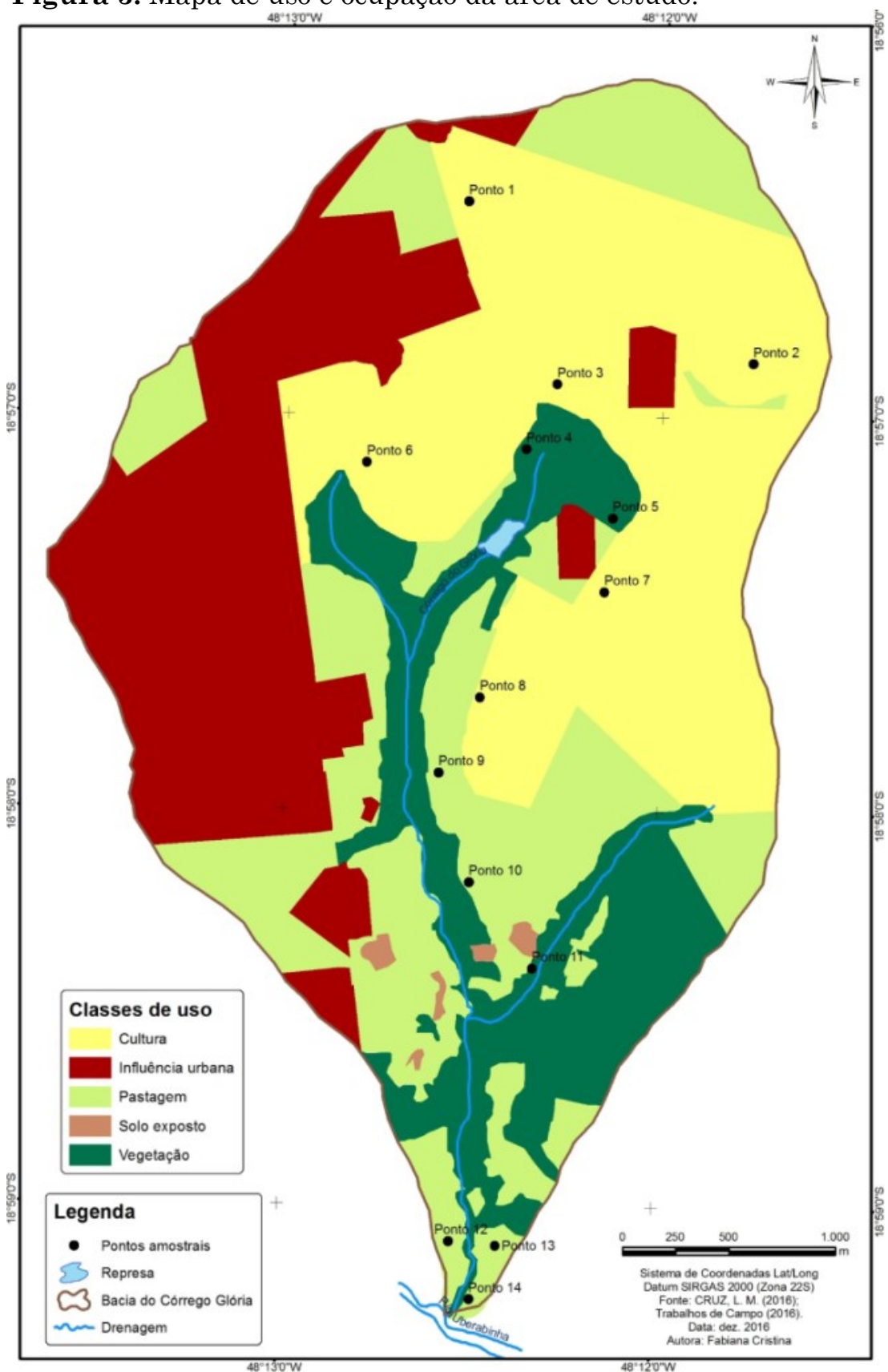

Org.: autores, 2018 .

Tabela 3 - Distribuição do uso e ocupação na bacia hidrográfica

\begin{tabular}{ccc} 
Uso e Ocupação & ha \\
Cultura & 423,4 & 33,08 \\
Influência urbana & 308,9 & 24,14 \\
Pastagem & 330,3 & 25,81 \\
Material superficial exposto & 5,7 & 0,43 \\
Vegetação & 211,3 & 16,51 \\
TOTAL & $1.279,7$ & 100 \\
\hline
\end{tabular}

Org.: autores, 2018 
Observa-se que somatório das áreas destinadas à exploração agrícola $(33,08 \%)$, pastagem $(25,81 \%)$ e influência urbana $(24,14 \%)$ representam $83,03 \%$ das áreas investigadas na bacia hidrográfica. Já a área ocupada por vegetação totalizam apenas $16,51 \%$ da bacia em questão. Há de considerar, que a susceptibilidade dos materiais superficiais, em virtude da ausência de cobertura vegetal, representa significativo agravante nos processos de degradação dos recursos hídricos da bacia hidrográfica em estudo.

Embora representem apenas $16,51 \%$ da bacia, a vegetação exerce um papel fundamental na preservação e manutenção da qualidade dos materiais superficiais e da água. Pela análise visual do Figura 3, fica nítida a diminuição e descontinuidade das matas de galeria que margeiam toda a extensão do Córrego do Glória, resultante de interferências antrópicas na abertura de novas áreas agrícolas.Assim, evidencia-se pelo exposto a destinação quase que exclusiva das áreas da bacia hidrográfica para fins de atividades agropecuárias.

Os resultados obtidos a partir da análise granulométrica das amostras coletadas na bacia hidrográfica estão apresentados nas Figuras 4, 5 e 6 . Nestas figura é visualizado o comportamento da espacialização das amostras, que deve-se a composição de partículas individuais interligadas nos materiais superficiais, demonstrando que grande parte das reações dos materiais superficiais, são atribuídas a fenômenos de superfície, como por exemplo adsorção de íons.

$\mathrm{Na}$ fase sólida dos materiais superficiais, mineral e orgânica, as reações químicas acontecem, devido à existência de cargas elétricas de superfície positivas e negativas, que atraem ânions e cátions, respectivamente. Assim, observa-se maior valor para argila, com $90 \%$ de composição, por tratar-se da menor fração do material superficial, denominada também de coloide. (Figura 4). 
Figura 4:Distribuição espacial de argila na bacia hidrográfica.

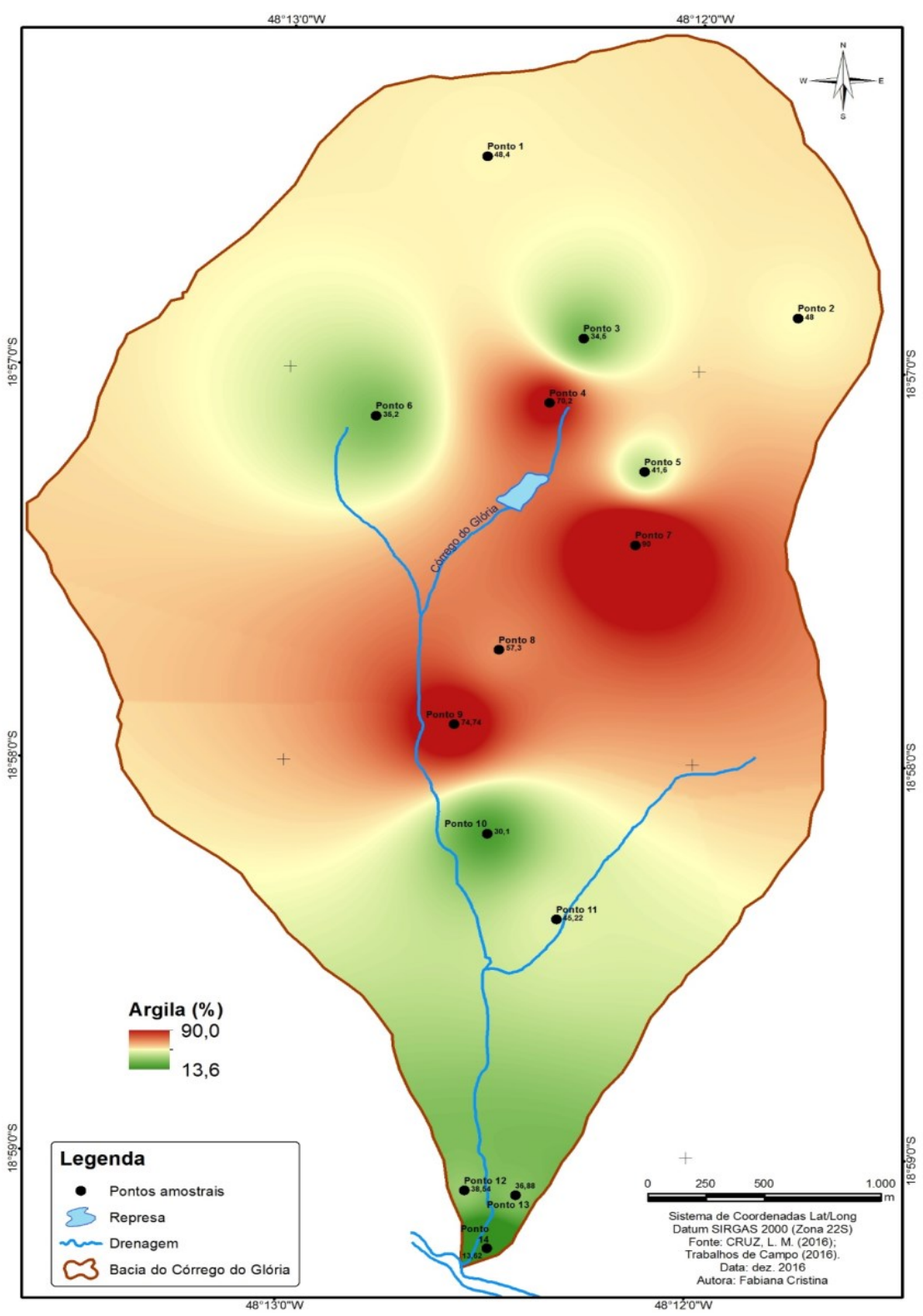

Org.: autores, 2018.

Isso demonstra que este atributo, dentre aqueles que compõem a textura dos materiais superficiais, é o que apresenta menor variabilidade e maior continuidade espacial, garantindo melhor precisão nas estimativas em locais não amostrados.

A relação silte/argila, apresentou variação regular. Em geral aqueles que apresentaram valores menores indicaram maior grau de intemperismo.(Figura 5) 
Figura 5- Distribuição espacial do silte na bacia hidrográfica.

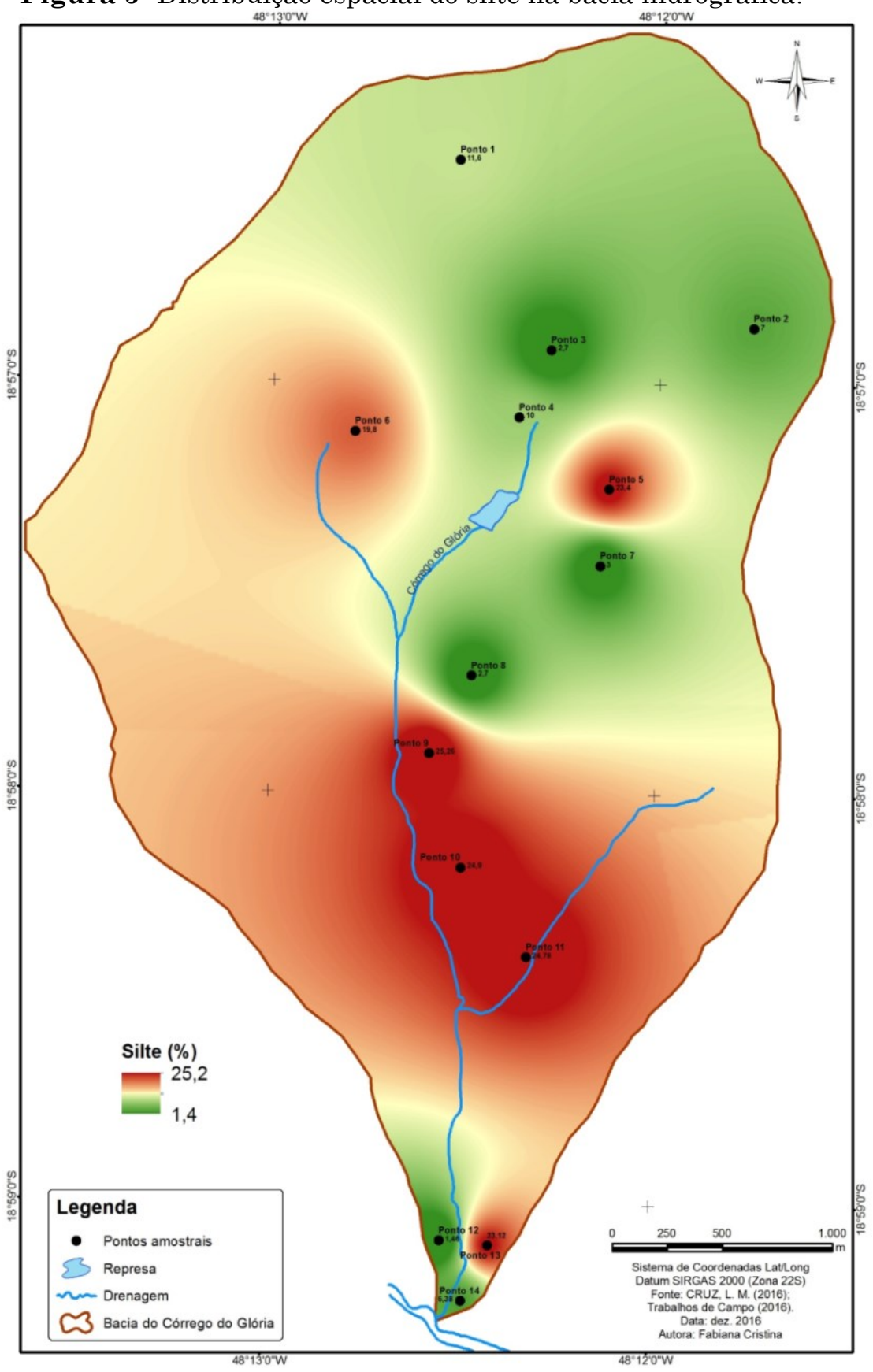

Org.: autores, 2016.

Já os teores de areia (Figura 6) foram maiores nas áreas de vegetação e pastagem (Figura 3), quando comparados aos demais. Esse comportamento é devido a influência do substrato geológico. 
Figura 6:- Distribuição espacial de areia na bacia hidrográfica.

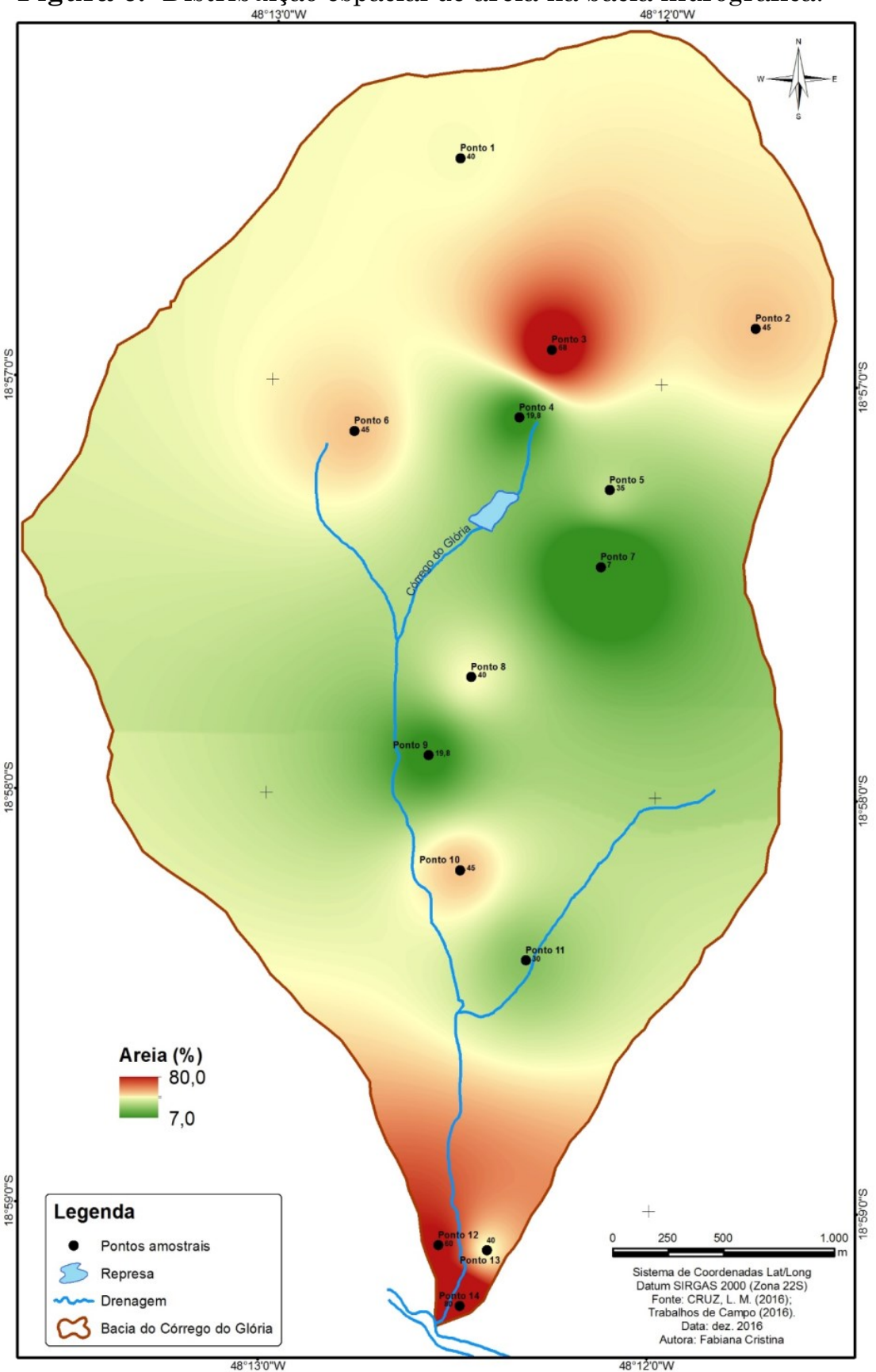

Org. autores, 2016.

O padrão de distribuição da densidade aparente, demonstrou-se heterogêneo, evidenciando variabilidade nos valores: com 6 pontos iguais a $1,2 \mathrm{~g} / \mathrm{cm}^{-3}$ e 7 pontos de $1,4 \mathrm{~g} / \mathrm{cm}^{-3}$ entre os pontos amostrais investigados conforme Tabela 4. 
Tabela 4: Atributos físicos da área de estudo.

\begin{tabular}{|c|c|c|c|}
\hline \multicolumn{4}{|c|}{ Profundidade } \\
\hline & $0-10 \mathrm{~cm}$ & $0-10 \mathrm{~cm}$ & $0-10 \mathrm{~cm}$ \\
\hline Pontos & $\operatorname{DA}\left(\mathrm{g} / \mathrm{cm}^{3}\right)$ & MO(dag.kg-1) & Porosidade\% \\
\hline 1 & 1,30 & 1,0 & 40,0 \\
\hline 2 & 1,30 & 1,0 & 45,8 \\
\hline 3 & 1,28 & 1,0 & 46,0 \\
\hline 4 & 1,13 & 1,0 & 40,5 \\
\hline 5 & 1,39 & 1,0 & 25,2 \\
\hline 6 & 1,40 & 1,0 & 40,0 \\
\hline 7 & 1,12 & 1,0 & 45,0 \\
\hline 8 & 1,55 & 1,0 & 20,0 \\
\hline 9 & 1,50 & 1,0 & 43,7 \\
\hline 10 & 1,37 & 1,2 & 44,0 \\
\hline 11 & 1,75 & 1,2 & 35,0 \\
\hline 12 & 1,35 & 1,2 & 76,0 \\
\hline 13 & 1,32 & 1,2 & 48,0 \\
\hline 14 & 1,23 & 1,2 & 47,0 \\
\hline
\end{tabular}

Org.: autores,2018.

A variabilidade de valores da densidade aparente na profundidade de 0-10 cm pode ser atribuída à maior exposição desta profundidade à movimentação dos materiais superficiais restrita principalmente nas áreas de cultura e pastagem, bem como ao tráfego de máquinas. Segundo Greenwood e Mckenzie (2001), a densidade e a porosidade são as propriedades físicas mais amplamente utilizadas na quantificação dos atributos físicos dos materiais superficiais.

A porosidade apresentou maior valor no ponto 12, valores intermediários nos pontos 1,2,3,4,6,7,9,10 e 14 e valores baixos nos pontos 5 , 8 e 11(Tabela 4). Pode-se considerar que a porosidade, cujo, valor maior (ponto $12 ; 76 \%$ ) foi encontrado na classe arenosa, refletindo seu caráter menos denso e menos coeso,tratando-se de área com presença de vegetação, como observado no mapa da Figura 4. Esta análise são semelhantes ao trabalho Dambrós (2012), que fez estudo em área florestada constituída por arenitos.

A partir da comparação do padrão de distribuição espacial da porosidade total e os atributos geomorfológicos como altitude e declive (Tabela 4), pode-se observar uma maior influência do relevo na distribuição espacial das frações areia e argila. Isto demonstra o comportamento diferenciado das frações areia grossa e areia fina em função da dinâmica da água e relevo, denotando a importância da subdivisão da fração areia em estudos pedogeomorfológicos. 
O maior tamanho da fração areia não favorece seu transporte a grandes distâncias, ao contrário da argila, que é transportado mais facilmente pelo escoamento superficial da água. Isto posto, pode-se sugerir um efeito de aumento do volume de água pelo fluxo acumulado nas vertentes, como principal agente condicionante de zonas com materiais superficiais mais arenosos, e portanto com maior porosidade total. Ademais, a perda de partículas mais finas dos materiais superficiais com tamanho das frações silte e argila, assim como a matéria orgânica durante a o escoamento superficial podem resultar na maior perda de nutrientes.

A análise da matéria orgânica, com base nas médias, mostra que a quase a totalidade dos pontos apresentam teor de matéria orgânica de 1,0 dag.kg-1 (Tabela 4), sendo este de alta suscetibilidade à erosão (GREENLAND et al., 1975 in GUERRA, 2007). Essa característica também tem relação direta com a textura arenosa dos materiais superficiais encontradas na pesquisa. Materiais superficiais com textura fina contêm mais MO. Eles têm uma melhor retenção de água e de nutrientes fornecendo condições ideais para o desenvolvimento das plantas. Já materiais arenosos são mais arejados e com uma decomposição mais rápida da $\mathrm{MO}$, pela presença do oxigênio.

Vale salientar que a dinâmica da matéria orgânica sofre influência do uso e ocupação, clima e características dos materiais superficiais, com destaque para textura. Nesse contexto o revolvimento e o tráfego de máquinas, reduz a cobertura vegetal, maximizando os riscos de erosão e afetando diretamente o índice de matéria orgânica.

Em estudo realizado em veredas localizadas em dois ambientes distintos, Ramos (2008) verificou que a matéria orgânica se apresenta como grande contribuinte para a fase sólida dos solos do terço inferior das vertentes das veredas de ambos os ambientes mas principalmente do terço inferior das vertentes das veredas de chapada.

O mesmo autor apresentam resultados em que os teores de $\mathrm{MO}$ também são maiores na camada superficial dos terços médio e superior das vertentes dessas veredas. Também se observou, em vereda estudada no estado de Minas Gerais, na zona de borda da área (região mais elevada), no limite com o cerrado, a ocorrência de melhor drenagem e, em contrapartida, menor teor de matéria orgânica (Guimarães et al., 2002). 
Este fato decorre, provavelmente, da decomposição e mineralização mais intensas da matéria orgânica, observadas numa condição de melhor aeração.

Os resultados dos atributos químicos estão descritos na Tabela 5. Os valores da Capacidade de Troca Catiônica (CTC), variaram entre 8,9 e 2,2 cmol.dm ${ }^{-3}$. O valor de CTC possui intrínseca relação com matéria orgânica e teor de argila. Dessa forma o ponto 7 apresentou maior valor desse atributo, $7,92 \mathrm{cmol} . \mathrm{dm}^{-3}$, justificado pela teor de $80 \%$ de argila e posição em área de cultivo (Figura 3 e 4).

Tabela 5 - Análises das propriedades químicas dos materiais superficiais da bacia hidrográfica.

Profundidade $0-10 \mathrm{~cm}$

\begin{tabular}{cccccc}
\hline Pontos & $\mathrm{K}\left(\mathrm{cmol}_{\mathrm{dm}}^{-3}\right)$ & $\mathrm{H}+\mathrm{Al}\left(\mathrm{cmol.dm}^{-3}\right)$ & $\mathrm{pH}\left(\mathrm{H}_{2} \mathrm{O}\right)$ & $\mathrm{CTC}\left(\mathrm{cmol}_{\mathrm{dm}}{ }^{-3}\right)$ & $\mathrm{V}(\%)$ \\
\hline 1 & 0,13 & 1,7 & 6,2 & 5,8 & 70,8 \\
2 & 0,21 & 1,0 & 7,2 & 7,6 & 86,9 \\
3 & 0,22 & 1,8 & 5,6 & 4,2 & 57,3 \\
4 & 0,28 & 2,7 & 5,3 & 6,5 & 58,3 \\
5 & 0,07 & 2,4 & 6,6 & 3,0 & 19,2 \\
6 & 0,04 & 3,7 & 5,5 & 4,5 & 38,5 \\
7 & 0,12 & 3,8 & 5,2 & 6,1 & 46,7 \\
8 & 0,08 & 2,6 & 5,0 & 4,9 & 43,0 \\
9 & 0,08 & 1,7 & 5,4 & 3,0 & 25,0 \\
10 & 0,1 & 2,1 & 6,0 & 2,8 & 24,4 \\
11 & 0,05 & 1,7 & 5,9 & 2,2 & 66,2 \\
12 & 2,3 & 2,0 & 6,1 & 5,9 & 36,2 \\
13 & 0,6 & 2,4 & 5,7 & 3,8 & 32,4 \\
14 & 0,17 & 6,0 & 5,2 & 8,9 & \\
\hline
\end{tabular}

Org.: os autores, 2018.

Maiores valores de CTC normalmente ocorrem em locais onde os teores de MO e argila são elevados (Figura 4). Esses atributos contribuem com o aumento de cargas negativas favorecendo, assim, a retenção de nutrientes. Outro fator que deve ser considerado na área estudada é a topografia, o que provavelmente, contribuiu com o acúmulo de argila e incremento da CTC nessa superfície. Nota-se portanto, uma heterogeneidade na distribuição espacial desse atributo.

Os menores valores de CTC, observados estão localizados nas áreas de pastagem e vegetação (Figura 3), o que também podem ser explicados pela 
ausência de calagem, bem como pelo avançado estado de degradação do sistema sob pastagem.

A saturação de bases (V), oscilou entre 86,9 \% e 18,5\% (Tabela 5). Ressalta-se que materiais superficiais nas regiões de cerrado, apresentam geralmente $\mathrm{V}<50 \%$, ou seja são distróficos. Os pontos 1, 2, 3, 4, 12 e 14 apresentaram valores maiores que $50 \%$, justificados por localizarem em áreas de cultura e pastagem, que já foram expostas à intervenções químicas por calagem. A textura arenosa mantém relação de proporção com os valores maiores que 50\% devido possibilitar a lixiviação das bases em solução.

Os valores elevados de saturação por bases (V) contribui para os altos valores de $\mathrm{pH}$ em água. Menores valores observados podem ser decorrentes da posição que favorece a adição dos íons das partes mais altas e diminuição das perdas por lixiviação, em razão da condição de drenagem.

Os materiais superficiais de regiões tropicais são normalmente ácidos e apresentam altos teores de $\mathrm{Al}$ trocável (Ronquim, 2010). O ponto 7 da Tabela 5 , apresentou maior valor $\left(3,8 \mathrm{cmol}_{\mathrm{cdm}} \mathrm{cd}^{-3}\right)$ e $\mathrm{pH} 5,5$. Explicação para tal fato está relacionado com a fração mineralógica e textural da região de estudo que predominam óxidos de $\mathrm{Al}$ e $\mathrm{Fe}$ tanto na forma cristalina (gibsita, goetita e hematita) quanto na forma amorfa. (Ronquim, 2010).

O alumínio trocável $(\mathrm{H}+\mathrm{Al})$ foi predominantemente formado pelos íons $\mathrm{H}^{+}$, uma vez que os teores de $\mathrm{Al}^{+3}$ não foram expressivos. Observa-se maior valor (ponto 14) de alumínio trocável na camada superficial (Tabela 5) indicando que a oxidação da matéria orgânica pode ser um componente importante na geração da acidez. Alumínio trocável apresenta comportamento inverso ao dos valores da saturação por bases, sendo maior na textura arenosa (Figura 6), confirmando valores obtidos por Nunes et al. (2001) que estudaram a relação solo-paisagem-material de origem em solos de Minas Gerais.

Quanto ao $\mathrm{pH}$ dos materiais superficiais, todos os pontos apresentaram $\mathrm{pH}$ inferior a 7,5 (Tabela 5), o que confere acidez aos materiais superficiais, comportamento normal da região de estudo. (OLIVEIRA, 2011).

Dos 14 pontos analisados, 8 pontos apresentaram acidez média, com valores variando entre 5,2 e 5,9 Diante desses resultados, ressalta-se a importância da cobertura vegetal ajudando os materiais superficiais a manter coesão entre suas partículas, já que observando os resultados de $\mathrm{pH}$ de forma 
isolada, os mesmo podem ser suscetíveis à erosão. Segundo Yoshioka (2005) a erosão também pode ser uma das causas da acidez, pois há a remoção da camada superficial, e esta possui maiores teores de bases e favorece a acidificação, expondo as camadas mais ácidas do subsolo. $\mathrm{O}$ menor valor de $\mathrm{pH}$ encontrado foi no P8, área de cultura apresentado $20 \%$ de porosidade e $1,55 \mathrm{~g} / \mathrm{cm}^{3}$ de densidade aparente.

A variação temporal do $\mathrm{pH}$ da solução e o seu comportamento, é verificado por uma ligeira redução nas áreas de pastagens e aumento na área de vegetação (Figura 3). Essa redução foi mais acentuada na área de pastagem sem cobertura vegetal, onde a lixiviação de bases mostrou-se mais intensa devido as área de culturas que são feitas calagens. A diminuição do pH da solução pode ser atribuída à elevação da concentração de $\mathrm{H}+$ no meio pelo aumento da decomposição da matéria orgânica, advinda da atividade microbiana com o início do período chuvoso após um período de seca

Os resultados do elemento químico potássio $\left(\mathrm{K}^{+}\right)$apresenta estreita relação com a classe textural arenosa (Figura 6). Esse comportamento devese, ao aumento do intemperismo, principalmente em condições tropicais, devido a mobilidade do potássio que mantém-se em solução. $\mathrm{O}$ pH mais elevado dos materiais superficiais favorece a troca de cátions e o aumento dos teores de $\mathrm{K}^{+}$. Na área em estudo pode-se constatar que, mesmo não recebendo qualquer adubação ou correção de acidez (área de vegetação), os valores de cátions trocáveis foram elevados.

$\mathrm{Na}$ medida em que as áreas passam a ser cultivadas, essas diferenças podem interferir no manejo da adubação. Os teores mais elevados de $\mathrm{K}^{+}$foram constatados no ponto 4 (Tabela 5); porém, não foi detectada dependência espacial, o que pode ser explicado pelo intemperismo dos materiais primários, haja vista que este elemento apresenta alta mobilidade que facilita seu transporte com o fluxo de água acarretando em características químicas diferenciadas na área.

\section{Considerações Finais}

Diante das análises foi possível chegar a algumas reflexões em relação à dinâmica físico-química da bacia hidrográfica enquanto objeto de estudo, incluindo as possibilidades de evolução dos materiais superficiais-paisagem que a região sugere: 
- $\quad$ variações na topografia geram influênciam sobre as propriedades dos materiais superficiais.

- Os materiais superficiais ao longo do tempo por ação do intemperismo são condicionadas pela posição na paisagem, devido a processos erosionais ou deposicionais, associados ao fluxo de água.

- Os atributos físico-químicos apresentaram dependência espacial com a textura e topografia.

Conforme já mencionado, a área vem sofrendo intensa ação antrópica devido a rápida expansão urbana da cidade de Uberlândia. O estudo físicoquímico ganha importância à medida que tenta caracterizar a sua espacialização, dinâmica e explicação das relações dos materiais superficiais com a paisagem, uma vez que traz a tona as possibilidades da evolução do relevo, assunto de interesse geomorfológico tanto para a academia quanto para os setores de planejamento.

A análise dos parâmetros físico-químicos na bacia hidrográfica, demonstra que a topografia e a posição da paisagem são relevantes uma vez que geram variadas influências nas propriedades dos materiais superficiais, mesmo quando estes são fortemente intemperizados e possuem um grau elevado de homogeneidade.

A analise da textura dos materiais superficiais na bacia, mostrou que as frações granulométricas em materiais superficiais são atributos pouco variáveis ao considerá-los ao longo do tempo por ação do intemperismo, sendo sua variabilidade condicionada pela posição na paisagem, devido a processos erosionais ou deposicionais, associados ao fluxo de água.

A cartografia de uso e ocupação da terra aponta que a bacia hidrográfica do córrego do Glória apresentou mais que 80\% de ocupação antrópica e agropecuária. Entretanto, a predominante cobertura florestal ainda funciona como protetora dos materiais superficiais contra a formação de processos erosivos.

As técnicas de análise por krigagem facilitaram a avaliação da variabilidade espacial dos atributos físico-químicos dos materiais superficiais tanto para bacia hidrográfica quanto para vertente. Os atributos físico- 
químicos apresentaram dependência espacial e correlacionaram-se respectivamente, com a textura e topografia.

Houve a preocupação com a aquisição de dados primários e secundários, com os mapeamentos, as análises dos materiais superficiais e as atividades de campo. Pode-se destacar a importância das atividades de campo realizadas na área e o uso das geotecnologias para o cumprimento dos objetivos. Ficou evidente, a partir dos indicadores aqui adotados, a participação do homem, enquanto agente catalizador no processo de modificação da paisagem.

Destaca-se a importância das análises dos materiais superficiais, consideradas aqui como um dos indicadores para o prognóstico final. Conhecer as propriedades físicas e químicas, a partir dos resultados das análises laboratoriais, contribui de forma mais precisa para os estudos indicando sua dinâmica na paisagem, tanto à remoção como ao transporte.

\section{Agradecimentos}

Agradecemos ao $\mathrm{CNPq}$ pelo apoio a pesquisa através do processo $\mathrm{PQ}$ 302654/2015-1 e à CAPES pela bolsa de mestrado da 1a. autora.

\section{Referências}

AB'SABER, A. N. Os domínios morfoclimáticos na América do Sul: primeira aproximação. Geomorfologia, São Paulo, v. 52, p. 1-22, 1977.

ALVES, R. A. Monitoramento dos Processos Erosivos e da Dinâmica Hidrológica e de Sedimento de uma Voçoroca: estudo de caso na Fazenda do Glória na zona rural de Uberlândia- MG. Mestrado em Geografia - Instituto de Geografia, Universidade Federal de Uberlândia, 2007.

COSTA, Y. T.; BARCELOS, A. C. ; RODRIGUES, S. C. . Fire effects on soil and vegetation in a degraded Brazilian Savanna. MERCATOR Fortaleza, v. 17, p. 1-13, 2018. Disponível em: $<$ http://www.mercator.ufc.br/mercator/article/view/RMv17Txt16p1a16_2018en>. Accessed in: 18 out. 2018.

DAMBRÓS, C. Comparação da porosidade total, granulometria e condutividade hidraúlica de amostra de solo em área florestada e de campo. Revista Geonorte, Edição Especial, V.1, N.4, p.566 - 577, 2012.Disponível em: http://www.periodicos.ufam.edu.br/revistageonorte/issue/view/115. Accessed in: 20 de dez 2017.

EMPRESA BRASILEIRA DE PESQUISA AGROPECUÁRIA (Embrapa). Centro Nacional de Pesquisa de Solos. Manual de métodos de análise de solo. 2. Ed. Rio de Janeiro: Embrapa CNPS, 1997. 
GREENWOOD K. L, MCKENZIE B. M. Grazing effects on soil physical properties and the consequences for pastures: a review. Australian Journal of Experimental Agriculture 41, 2001,p.1231,1250. Disponível em: https://dl.sciencesocieties.org/publications/sssaj/abstracts/54/6/SS0540061682> Accessed in 19 de mai 2016. https://doi.org/10.1071/EA00102

GUERRA, A. J. T. Processos Erosivos nas Encostas. In: Geomorfologia - Uma Atualização de Bases e Conceitos. GUERRA, A. J. T. \& CUNHA, S. B. (orgs). Rio de Janeiro: Bertrand Brasil, $7^{a}$ edição, 2007, p. 149-209.

GUIMARÃES, A. J. M.; ARAÚJO, G. M.; CORRÊA, G. F. C. Estrutura fitossosiológica em área natural e antropizada de uma vereda em Uberlândia, MG. Acta Botanica Brasilica, v.16, p.317-329, 2002. https://doi.org/10.1590/S0102-33062002000300007

NUNES, U.R.; ANDRADE JÚNIOR, V.C.A.; SILVA, E.B.; SANTOS, N.F.; COSTA, H.A.O.; FEREIRA, C.A. Produção de palhada de plantas de cobertura e rendimento do feijão em plantio direto. Pesquisa Agropecuária Brasileira, v.41, p.943-948, 2001. https://doi.org/10.1590/S0100-204X2006000600007

OLIVEIRA, D. de. Técnicas de Pedologia. In: VENTURI, L. A. B. (org.). Geografia: práticas de campo, laboratório e sala de aula. Editora Sarandi: São Paulo, 2011, p. 83-106.

PINESE JÚNIOR, J. F.; CRUZ, L. M.; RODRIGUES, S. C. Monitoramento de erosão laminar em diferentes usos da terra, Uberlândia - MG. Sociedade \& Natureza, v. 20, p. 157-175, 2008. https://doi.org/10.1590/S1982-45132008000200010

RAMOS, A. L. L. S. Características Micromorfológicas de Latossolos Vermelho Amarelos da Porção Norte da Bacia do Córrego do Rio Grande, em Gouveia (MG). (Dissertação em Geografia) - Belo Horizonte - UFMG - 2008. Disponívelem:www.bibliotecadigital.ufmg.br/dspace/handle/1843/MPBB-

8BYNUR $>$ Accessed in 18 de mai 2016.

RODRIGUES, S. C. Análise da fragilidade do relevo. Abordagem empírico-experimental. Revista Sociedade \& Natureza. v12 n. 23, p.167-189, 2000.

RONQUIM, C. C. Conceitos de fertilidade do solo e manejo adequado para as regiões tropicais. Embrapa Monitoramento por Satélite, Campinas - São Paulo, 2010.

SANTOS, F. C. ; BARCELOS, A. C. ; RODRIGUES, S. C. . Distribuição de atributos físicos do solo sob vertente em ambiente de Cerrado nativo do Triângulo Mineiro / Cad. Geografia, v. 25, p. 66-77, 2015. DOI 10.5752/P.2318-2962.2015v25n43p66.

SANTOS, F. C.; RODRIGUES, S. C. Variabilidade espacial físico-química de materiais superficiais sob uma vertente de Cerrado em estágio de recuperação.Cad. Geografia, , v. 27, n. 48, p. 200-209, 2017. https://doi.org/10.5752/P.2318-2962.2017v27n48p200

YOSHIOKA, M. H.; LIMA, M. R. de. Experimentoteca de solos pH do solo. Projeto Solo

na Escola, 2005. Disponível em
http://www.escola.agrarias.ufpr.br/arquivospdf/experimentotecasolos7.pdf. Accessed in: 03 jan 2017 